Georgia State University

ScholarWorks @ Georgia State University

1996

\title{
Cultural Learning and Learning Culture
}

\author{
Ann Cale Kruger \\ Georgia State University \\ Michael Tomasello \\ Duke University
}

Follow this and additional works at: https://scholarworks.gsu.edu/ltd_facpub

Part of the Instructional Media Design Commons

\section{Recommended Citation}

Kruger, A.C., \& Tomasello, M. (1996). Cultural learning and learning culture. In D.R. Olson \& N. Torrance (Eds.), Handbook of education and human development: New models of learning, teaching, and schooling (pp. 369-387). Cambridge: Blackwell.

This Book Chapter is brought to you for free and open access by the Department of Learning Sciences at ScholarWorks @ Georgia State University. It has been accepted for inclusion in Learning Sciences Faculty Publications by an authorized administrator of ScholarWorks @ Georgia State University. For more information, please contact scholarworks@gsu.edu. 


\section{THE HANDBOOK OF \\ Education and Human Development}

New Models of Learning, Teaching and Schooling

Edited by

DAVID R. OLSON

and

NANCY TORRANCE 


\title{
PART B \\ Cultural Context of Human Development and Education
}

\section{7 \\ Cultural Learning and Learning Culture}

\author{
ANN C. KRUGER \\ MICHAEL TOMASELLO
}

The universals and cultural variations of human development have been the focus of fruitful study by anthropologists for decades. In recent years psychologists also have directed their attention, long overdue, to understanding development in cultural context. There are striking differences among psychologists, however, in the approaches they take to culture and development. Most markedly, Cole (1989) distinguishes two very different theoretical perspectives on cultural psychology and its approach to human development. In one perspective the focus is on culture as a collective enterprise (e.g., Gauvain, in press; Shweder, 1990; Super and Harkness, 1986). There is no need in this view for focusing on the individual development of individual children since all important forms of learning are socially distributed; children simply become more skillful over time at participating in various collective activities (Lave and Wenger, 1991). Indeed, in some versions of this more sociological view of cultural psychology the focus on the cultural collective is so strong that there is really no justification for reference to the development of individuals at all: "Individual, interpersonal, and sociocultural processes constitute each other and cannot be separated" (Rogoff, Chavajay, and Matusov, 1993, p. 533).

The other perspective on cultural psychology is more in line with traditional psychological approaches to the individual person in culture. In this view, it is important to distinguish individual children and the cultures into which they are born. A central focus of this approach is the competence that children bring to the process of enculturation and how this competence contributes to their internalization of various aspects of their cultures (Vygotsky, 1978). In this view an exclusive focus on the collectivity to the neglect of individuals makes it impossible to understand the cognitive development of such individuals as autistic children, 


\section{0

who never become very skillful at participating in collective activities, and nonhuman primates, who do not grow up in cultures at all (Tomasello, 1990).

Our own previous work has been decidedly within this more psychological, and less sociological, orientation to human development in cultural contexts. In 1993 , for example, we and Hilary Ratner proposed a theory of cultural learning that attempted to explain how children's developing social cognition leads to new forms of participation in cultural activities and thus to new ways of internalizing important aspects of their cultures (Tomasello, Kruger, and Ratner, 1993). For instance, we hypothesized that it was not until children could understand other persons as mental agents, with thoughts and beliefs that differed from their own, that they could engage in the kinds of internal dialogues of private and self-regulating speech that Vygotsky (1978) described some years ago - since such dialogues often presuppose two distinct mental perspectives on the same situation.

We have seen no data and heard no arguments to dissuade us from our more psychologically based view of cultural psychology. However, based on the responses to our ideas that we have received, especially from cultural anthropologists and cultural psychologists, it is clear that our theory of cultural learning as we originally formulated and presented it focused too narrowly on the cognitive capacities of the individual child. For a more balanced and complete theory, we need to complement our focus on what the child brings to the culture with a focus on what the culture brings to the child. We believe that there are two aspects of culture that will be especially important in formulating a more complete account.

First, it is important to emphasize, as we did not in our original account, the role in children's development of the preexisting structure of the culture: its games, institutions, rituals, cultural models, intentional scripts, and communal activities -in brief, its "habitus" (Bourdieu, 1977). Children are born into some version of this structure and these activities, and the particular version they are born into potentiates some forms of development and constrains or even disallows other forms of development. In many domains children develop culturally specific ways of acting that they do not explicitly set out to learn and that no one explicitly sets out to teach them; they simply participate in forms of activity structured by the culture and learn some ways of behaving and thinking as a result. Our previous account did not give adequate attention to the ways in which cultural patterns structure children's lives, and thus for many anthropologists it was woefully incomplete (Ingold, 1993). We mostly agree with this criticism.

Second, it is important to emphasize that culture sometimes imposes itself on children in the form of intentional instruction. In our previous account of instructed learning we explicitly took the child's point of view, defining instructed learning essentially as the child's internalization of adult instructions. We do not wish to change this perspective here, but it is necessary to supplement it with a fuller account of the process of instruction. In particular we need to respond to the criticism of our theory that we portrayed adult instruction in an excessively Western fashion. On the one hand, Rogoff et al. (1993; see also Foreman, 1993) argued that in some cultures there is basically no intentional instruction of children, and thus our entire treatment of instructed learning as the internalization of 
adult instruction was misguided. Olson and Astington (1993), on the other hand, simply pointed out that our treatment of instruction did not adequately explicate the adult side of the interaction, not taking into account the different types of instruction that exist in different cultures and the cognitive abilities that these require of the adult. We do not agree that there are cultures that do not intentionally instruct their young, as we hope to demonstrate in this paper, but we do agree that there are differences in the type of instruction employed in different cultures, and that these will have important consequences for children's development.

In this paper, we attempt to make our theory of cultural learning more complete by giving an account of the process of cultural learning not from the point of view of the child, but from the point of view of the culture. In the process, we try to address the two shortcomings of our theory just elaborated. First, we briefly discuss the role of preexisting cultural patterns as an important part of the enculturation process. We are brief on this score because there is no controversy here; we only wish to appropriate the ideas of many anthropologists who have emphasized this aspect of learning culture (e.g., Quinn and Strauss, 1994; Shweder. 1990). Second, we deal with instruction and instructed learning. In this case we must go into more detail because we have disagreements here with other cultural psychologists on several important issues, even over such fundamental points as the definition of intentional instruction. We conclude with brief discussions of the role of intentional instruction in cognitive development and the implications of our theoretical approach for processes of education.

\section{Individual Learning of Culture}

Tomasello, Kruger, Ratner (1993) went to great lengths to distinguish cultural learning from individual learning, but also, importantly, from other forms of social learning. For example, we argued that many animals are exposed to some learning situations that they otherwise would not be exposed to because they follow their mothers and other group members. Sometimes the changes of state in the world that adults bring about through their individual efforts (e.g., opening nuts) reveal to the developing youngster affordances of the environment that it previously did not know existed (e.g.. that nuts can be opened and have something edible inside). We call this emulation learning.

Our definition of cultural learning, however, singles out those instances of social learning in which the child learns something more deeply social than the physical fact that nuts can be opened. In cultural learning children learn not just about affordances of the inanimate environment but also something about the intentional states of adults - what they intend to do in performing certain actions or, perhaps, the strategy they are using or thoughts they are thinking. In cultural learning the child does not learn from the adult's actions, but the child learns through the adult's perspective in a truly intersubjective fashion. It is also important in our definition of cultural learning that on many occasions children internalize adults' intentional attitudes from such encounters and make them their own. Within this definitional framework we identified three types of cultural 


\section{2

learning: imitative learning, instructed learning, and collaborative learning. The fact that these three types of learning emerge in human ontogeny in an invariant developmental sequence-imitative, instructed, collaborative-was explained through references to the different levels of understanding of the intentional states of others that children of different ages are able to employ - specifically, the understanding of others as intentional agents, mental agents, and reflective agents.

In our original paper we were quite explicit that cultural learning may only account for a few of the child's learning experiences. Its importance lies in the fact that it enables many uniquely human cultural activities and artifacts - for example, the learning and use of conventional symbols and language. However, it is clear that children learn many other things about culture in ways that do not invoke such intersubjective forms of interaction and learning. Following Bourdieu (1977), Quinn and Strauss (1994) refer to the habitus of culture, the cultural "schemas" that lead children down certain culturally specific developmental pathways. For example, children in traditional hunter-gatherer societies are exposed to a particular set of practices during infancy, one of which is being carried in close contact with their mother's body throughout the day. At a very young age the babies become familiar with the smell of their mother's skin, the sensation of being carried as she walks, the warmth of the sun on their scalps, the touch of the sack they are carried in, and the taste of breast milk. As the babies develop, their experiences multiply, but those experiences are always delimited. For children growing up in various cultures, what will become familiar or "second nature" will be based on the particular set of experiences that define their young lives. The habits, attitudes, and ways of looking at the world that these experiences engender are not something that the adult sets out to teach or something the child sets out to learn. They are just a part of the habitus of a particular society that the child, over time, joins.

It is interesting that other species also may learn the patterns of their social group in this same way. Thus many behavioral ecologists refer to chimpanzee "culture" (e.g., see Wrangham, McGrew, deWaal, and Heltne, 1994). What they are describing with this term is a number of intergroup differences in the behavior of chimpanzees in the wild, differences in habits such as foods eaten and tools used. But, as argued before (Tomasello, Kruger, and Ratner, 1993), based on a wide variety of evidence, it is not very likely that chimpanzees engage in cultural learning narrowly defined (see also Tomasello, 1994). However, it is possible that they are learning the habitus of their group, which, like the human counterpart, includes all of the group's habitual ways of acting. Thus a chimpanzee youngster in one group follows its mother to a termite mound and finds holes containing sticks with termites crawling on them, while a youngster in another group follows its mother to nut trees and finds stones and half-opened nuts. The point is that many animals are excellent individual learners, and if different groups of a species adopt different behavioral practices as adaptations to their particular local ecologies (or for whatever reasons), then their offspring will experience different sets of learning experiences.

Nevertheless, the way humans engage in this process may still have two 
species-specific features. First, and perhaps more importantly, children have not just the physical environment as their habitus but also various social activities and even cultural institutions that lead them to have highly specific learning experiences. For example, children in some cultures grow up in the company of a large extended family; life is communal and materials and activities are shared with siblings, cousins, grandparents, and others. Other children grow up in cultures in which individuals possess private property and in which many activities are performed with just a few others, or even alone. The communal or private structures of these cultures channel children's experiences in particular ways.

Second, human children "soak up" not just the outward practices of their group but also, by inference, the values and attitudes of their group. For example, in cultures in which children sleep in the same room with their parents, children may deduce the importance of closeness and communality, without anyone explicitly expressing those values. In cultures in which children sleep in their own rooms, children may infer respect for individuality and privacy, all on their own. It is possible that other animal species do not have such inferencing capacities, which means that the transmission of the habitus of the group to the developing individual has a wider range of influence in the human species.

Through this discussion of habitus, then, we wish to supplement our theory of cultural learning with an account of the individual learning of cultural patterns. It is very likely that, if quantification of such matters were possible, the individual learning of culture contributes "more" to the differences among members of different cultures than cultural learning in our very specific definition. Nevertheless, we maintain that many uniquely human abilities are only possible through cultural learning as we originally defined it. Moreover, we must also point out that many of the cultural patterns that children individually learn in the habitus of their cultures are patterns that were originally created through processes of cultural learning, especially collaborative learning. That is to say, such things as farming practices that a child may come to learn more or less individually through participation, were first invented by individuals collaborating with one another in an intersubjective manner.

\section{Intentional Instruction of Culture}

Our earlier work was also criticized for implying that intentional instruction is a human universal (Rogoff, Chavajay, and Matusov, 1993). The contention is that many traditional societies do not practice intentional instruction since their education is informal: children learn by observing their elders' activities and by their own practice in the flow of everyday life (Bruner, 1972; Childs and Greenfield, 1980). It is children who assume the responsibility for learning; adults do not intentionally teach them (Greenfield and Lave, 1982).

We believe that this position is untenable, both definitionally and factually. Definitionally, we contend that informal education is also an instance of intentional instruction, and so our proposal that intentional instruction is a human 


\section{4

universal is clearly true. But in addition, we contend, factually, that all cultures engage in formal education; it is just that some of them do so only in a few, circumscribed contexts. To support these contentions we will (1) propose a definition of intentional instruction, (2) identify three different processes of intentional instruction, and (3) provide evidence that all cultures engage to some extent in all three of these processes.

\section{Intentional Instruction in Comparative Perspective}

Adults in our nearest primate relatives do all kinds of things that serve to promote the acquisition of particular skills. For example, chimpanzee mothers often walk away from their young infants at the age at which they are just beginning to selflocomote (Goodall, 1986). If the infants do not follow, the mothers stop, look back, and sometimes make noises of frustration. If the infants now follow the mother, it can be said that she has encouraged their self-locomotion. But it could also be said that she wishes to travel and is frustrated that the infant is not following as it should. Thus it can be said that the mother's intentions are that the baby follow her, not that the baby learn something. The same can be said of the well-known example of chimpanzee mothers taking poisonous leaves away from their infants (Goodall, 1986): She intends for them to refrain from eating the leaves, not for them to learn to refrain from eating the leaves.

The point is that teaching is a behavior that can only be adequately defined by its intention. We can refer to all behaviors of one animal that serve to facilitate some behavior by another as "teaching" (e.g., as Caro and Hauser, 1992), but it then loses all of its meaning. Teaching is a behavior in which one animal intends that another learn some skill or acquire some bit of information or knowledge that it did not have previously. Such an intentional definition is not hopelessly unverifiable; rather it is quite easily identified. The teacher needs to behave in ways that are adapted to the skill level of the learner, for example, providing more and different kinds of instruction when the skill level is low, changing as the learner becomes more skillful, and ceasing when the skill level becomes self-sufficient. In any case, if we restrict our definition of teaching to intentional forms - or if we posit a subcategory of teaching termed intentional teaching - then the most serious candidates from the nonhuman world are those that have been recently reported by Boesch $(1991,1993)$.

For almost a decade Boesch has been observing chimpanzees in western Africa as they crack and eat nuts - which they do on a daily basis during certain seasons of the year. They place one of several varieties of nut on some type of rigid substrate such as a stone or root (called the anvil) and then pound it with either a stone or hefty stick (called the hammer). It is not an easy skill for youngsters to learn and it typically takes them several years of practice (during the one- to five-year age range) before they attain adult-like skill levels. In this context Boesch has observed a number of ways that the behavior of mothers serves to facilitate the nut cracking of their offspring. In line with an intentional definition, he has divided his observations into "facilitation" and "active teaching." Observations of facilitation are 
fairly common and consist mainly of mothers allowing their infants to use their hammers or nuts (which they tend not to let other animals do). This behavior is consistent with mothers allowing children to take food from their hands (which they also do not allow others to do). In his decade of observation Boesch has seen only two instances of what he considers active teaching. They are important enough that we will cite them each at some length (paraphrased from Boesch, 1993. pp. 176-177).

(1) A mother was cracking some very hard nuts, with her son eating most of them. The son then tried to crack some nuts for himself, with limited success. At one point he placed a partly open nut on the anvil in a way not conducive to successful opening. Before he could strike the nut, however, his mother picked it up, wiped off the anvil, and placed it on the anvil in the correct position. The son then successfully struck and opened the nut.

(2) A daughter was attempting unsuccessfully to open nuts with an irregularly shaped hammer. Her mother then joined her. The daughter pushed the poor hammer to the mother. The mother then, in a very deliberate manner (for over one minute), rotated the hammer into its best position for pounding the nut. She then successfully opened a number of nuts, with both mother and daughter eating them. The mother then left and the daughter proceeded to make attempts on her own, with mixed success but always with the hammer in the orientation her mother had used.

Boesch claims that in the first example the mother anticipated her son's impending failure and intervened to ensure his success. Perhaps. But it is also possible that she noticed from her own previous experience that the nut was not correctly positioned and positioned it for herself, which her son then exploited. Boesch interprets the second example as the mother correcting her daughter's mistake and demonstrating the correct method. Again, perhaps this is correct, but it is also possible that the mother was simply using the hammer to crack nuts for herself as she normally would. The only behavioral evidence for the instructional interpretation of this observation is that the mother very slowly rotated the hammer into the most efficient position for her own cracking attempts. And even if the mothers were intending that their infants successfully crack a nut on these singular occasions, the intention that the child succeed is still different from the intention that they learn. In any case, these two isolated observations would be much easier to interpret if they fell into a larger pattern of instructional activity in this and other contexts in the chimpanzees' lives. For now, we remain skeptical that the mothers' intentions were to help their infants learn to crack nuts efficiently.

Overall, the difference between human intentional instruction and all of these examples from nonhuman primates is that human adults do whatever is necessary so that children will learn skills for themselves, and then, when children attain a certain level of skill, withdraw. If a child is not successful initially, the adult keeps at it, adjusting instruction as necessary, with the child's self-sufficient competency as a goal. Moreover, as Bruner (1993) points out, in many situations of human life there is an onus placed on children: Children are expected to learn from the instruction, perhaps so that they can eventually be helpful to adults, and are dealt with harshly if they do not. Human pedagogical intentions thus make 
themselves manifest both in adults' propensity to show children how to do things, and in the adults' expectation that children will become more self-sufficient and competent as a result.

\section{Three Processes of Intentional Instruction}

Although all human societies expect their children to learn, what varies both within and between cultures is the adults' beliefs about how this learning will take place and about the degree to which active instruction is necessary. We hypothesize three types of adult theory of child learning and consequent level of adult involvement in education. These hypothesized types are actually prototypes, hypothetical pure cases. We recognize that real life is less pristine than our theory; indeed, the nature of these adult beliefs as they actually exist may resemble our prototypes, or they may be on the borderline between two types or a mixture of types. We take the risk of oversimplification for the heuristic benefits that accrue, and we argue that to some degree these three types are present in all human societies.

First, adults believe that children "come up" to master some skills on their own. They assume that children are competent learners just as they are competent growers. This expectation arises from the theory that nature provides for learning, just as it does for growing, and that adult participation is not required in either process. Adults in these cases are not indifferent to children's learning; in fact, their interest in learning is profound enough to produce a theoretical understanding that guides practice. Should their theory prove faulty in some instances, adults will adapt both theory and practice to make sure that children learn. For example, in most Western cultures the skill of walking is expected to develop naturally, but if it does not, adults intervene in the process. This expectation of learning, and the intention to provide for it if the need arises, distinguishes human adults from the adults of other primate species, as described above. The adults' approach to education in these cases may be called laissez-faire, and it is present when the skill to be learned is not highly valued or when it is simple. We call this educational style expected learning because adults anticipate that children will learn on their own, that learning will happen naturally.

Second, adults believe that children need guidance to learn complex or valued tasks, that they need to "bring up" their children to master certain skills. They feel that although children might eventually learn such skills on their own, their intervention enables children's acquisition of challenging skills more rapidly and efficiently. In some cases the adult requires the child to observe a particular practice at a particular time. In other cases the adult allows the child to participate in the task to the extent to which the child is currently able. The adult might simplify the task, adding more demonstration or explanation when necessary, and increase difficulty and reduce assistance as the child progresses. This type of practice is easily distinguishable from "teaching" by other primates because it is so clearly intentional; the adult persists in the practice until the child is successful. This level of adult involvement may be called scaffolding; it requires sensitive observation of 
Table 17.1 Three types of intentional instruction and their associated adult beliefs and activities

\begin{tabular}{lllll}
\hline & Adult beliefs & Adult activities & Types of tasks & Types of practice \\
\hline Expected learning & $\begin{array}{l}\text { Learning occurs } \\
\text { through } \\
\text { maturation }\end{array}$ & Laissez-faire & $\begin{array}{l}\text { Simple or } \\
\text { not valued }\end{array}$ & Informal \\
Guided learning & $\begin{array}{l}\text { Learning needs } \\
\text { assistance }\end{array}$ & Scaffolding & $\begin{array}{l}\text { Moderately } \\
\text { complex or } \\
\text { valued }\end{array}$ & Semiformal \\
\hline & $\begin{array}{l}\text { Learning needs learning } \\
\text { insistence and } \\
\text { direct } \\
\text { instruction }\end{array}$ & Teaching & $\begin{array}{l}\text { Highly complex } \\
\text { or valued }\end{array}$ & Formal \\
\hline
\end{tabular}

the child's performance and attention to the child's experiences to enhance learning. This type of practice is semiformal, falling between informal and formal in the quantity and quality of structure provided. We call this educational style guided learning, because children's efforts at learning benefit from adults' assistance.

Third, adults believe that in some situations learning must be created, that they must effortfully "pull up" their children to certain skills and standards. They assume that children alone will never be able to master highly complex, abstract, or valued tasks and that precise instruction is necessary to prepare for eventual mastery. The adult understands the uniqueness and importance of the tasks and understands that it is virtually impossible to learn these tasks by methods other than those that are the most motivating and persuasive. Consequently, the adult's level of involvement is high, designing a special setting for the learning and communicating the information in a systematic way. This type of practice is formal, and the adult's activity may be termed teaching. We call this educational style designed learning, emphasizing the responsibility of the adult to effortfully create the learning situations. While designed learning is not used by all cultures in all situations, it is used by all cultures in some domains, as we show in the section that follows. A summary of these three types of instruction appears in Table 17.1.

\section{Intentional Instruction in Different Societies}

To check for the presence of these three levels of adult involvement in the education of children, we surveyed the anthropological literature for several human societies. These societies have a wide geographic distribution and range in polity types from camps (foragers like the !Kung San of Botswana) to chiefdoms (traders like the Puluwatans of the Western Caroline Islands) to people living within states (like the Chaga living on the slopes of Mount Kilimanjaro). Nearly all are nonliterate societies. More specifically, these cultures were selected to test the hypothesis that 


\section{8

even the smallest-scale society features intentional teaching of children, if only for a few and special tasks.

Expected Learning People living in small-scale societies are widely believed to have a hands-off attitude toward the education of children. This is true for many tasks and skills, often because they are assumed to develop naturally. For example, the Tallensi of Taleland in northern Ghana, West Africa, live in a small-scale farming society. According to Fortes (1970), life skills (e.g., chopping, carrying, washing) are acquired via the Tallensi children's participation in the ongoing flow of activity. The adults assume that skills develop with practice, just as the body grows with time. Children are thought to be capable and desirous of learning, so the adults stay out of the process. About child development, the adults remark, "Naawun mpaan ba [heaven teaches them]" (p. 37). Similarly, the Manus people of New Guinea (Mead, 1930) assume that physical skills, and even grace, develop naturally. Although their world presents many physical challenges to young children, they are never taught. The children learn to swim, to walk over treacherous wooden slats, to canoe, and many other skills by straightforward immersion and participation in the activities.

On the island of Samoa, adults believe that children learn best when they are left alone to observe and adopt adult behaviors over time. Consequently, adults make few accommodations to young children. For example, Samoan parents do not simplify their speech when they address their sons and daughters. Instead, they expect the children to come up to adult speech standards on their own. The adults believe that for children "the way to knowledge and power is to serve (i.e., attend)" (Ochs, 1988, p. 205). The !Kung San of the Kalahari Desert in Botswana (Konner, 1982) claim that infants cry because they have no "sense." There is no use for adults to try to stop the babies from being senseless. The !Kung believe that when the babies grow older they will develop sense on their own. This expectation of maturation constitutes a belief about how the child changes with age. It is important to note, however, that if the belief is violated by experience, as when a child fails to learn on its own an important task, such as food gathering, adults behave differently. They adjust their theory and become more assertive about the need to learn. In such an instance, !Kung adults make a piquant comment, such as, "Maybe this child doesn't like to eat" (M. Konner, personal communication, 1994). The implication of this usually requires no further elaboration for the child. As we see in this example, the societies that possess maturational theories of child development and who sometimes practice laissez-faire education also have other theories about development and other levels of involvement, depending on the particularities of the individual, the task, and its domain.

Guided Learning There is evidence that adults in all cultures believe children need a careful, graduated program of guidance to learn at least some more complex skills. In these circumstances, adults expect children to eventually learn, but they scaffold the child's acquisition of ability nevertheless. For example, Tallensi young people serve as apprentices to skilled practitioners, such as leatherworkers. 
Although the apprentices learn mostly by observation and participation in the practice, they also are given explanations by the masters when necessary (Fortes, 1970). Mayan mothers simplify the task of tortilla making for their daughters; they give pointers, make demonstrations, provide suggestions, and adjust the task to increases in skill (Rogoff, 1990). Early in their career, Liberian apprentice tailors are allowed to work on parts of clothing that are inexpensive (in case they botch the job) and on pieces of the material that do not show (Greenfield and Lave, 1982). With time and improved skills, they are given more important work, eventually being trusted to make entire articles of clothing. In Mexico, Zinacanteco girls learn to weave by observation and active participation, but they receive simplified situations, corrections, and help from the adults (Childs and Greenfield, 1980), and the support supplied by adults varies inversely with the skill level of the learner. Adult structuring of learning situations can be quite subtle. In some cases adults simply encourage observation generally; in other cases they may point out certain events for particular notice (Rogoff et al., 1993). Scaffolding also can be nonverbal, as when a Rotuman parent in Melanesia simply adjusts a child's body position during a task (Howard, 1970), or when a parent makes a tiny bow for a little boy to practice hunting or a tiny bucket for a young girl to use in carrying water (Fortes, 1970).

These are examples of semiformal, scaffolded interaction, in which the adult intervenes to prevent the learner from going hopelessly off track, from ruining a piece of work, or from becoming discouraged. The adult's expertise is valuable to the child, and the child's productivity is valuable to the adult. The children are not expected to reinvent weaving or tailoring or leatherworking on their own, or to learn them perfectly by observation and practice. Part of the adult's motivation is economic, no doubt, but this economic need for a productive helper coincides with their theoretical and empirical understanding of what will happen if the apprentices are left to their own devices.

It is our contention that scaffolding is intentional instruction. The adults expect the children to learn, but they also expect that they will have to intervene in order to produce a skilled helper. The adults provide help in a graduated manner that reflects their monitoring of the child's developing capacity for more independent work. Thus the adult's behavior reflects a theory that the learner must be active in the flow of practice from the beginning, but that the learner's perspective on the task will be immature. The expert must then carefully structure the learning experiences to match the child's changing perspective.

Designed Learning There is evidence that highly valued skills are carefully taught, even in traditional societies. Super (1981) reports that valued physical skills such as sitting and walking are deliberately taught to babies in most traditional African cultures. For example, sitting is taught by placing the infant in the upright position supported by cloths, or by placing the infant in a shallow hole that supports the sitting position. This teaching takes place every day for several months before the expected age of performance. Clearly, these adults in traditional, nonliterate cultures are not only practicing laissez-faire education or even scaffolding. They 
are actively, intentionally teaching their infants these skills, outside the casual practice of them, even before the infant can attempt these skills alone.

The practice of hunting among the !Kung is both highly valued as a food source and highly complex in the skills required. Boys are given tiny bows for practice, and they are allowed to tag along and participate with the adults as they can. However, their hunting education also includes periods of storytelling and question-and-answer sessions conducted by experts, back in camp (Konner, 1981). These are times for hunting instruction that are set apart from the everyday practice of these skills. The adults behave in a way that reflects their belief that their knowledge is important, abstract, and essential to the hunting education of the children.

One of the most impressive displays of teaching can be found among the Puluwat people of the South Pacific (Gladwin, 1970). The Puluwats design and build oceangoing canoes and navigate vast expanses of open ocean by dead reckoning. Their skills are formidable, and they pass them on to the next generation in a highly formal manner. Apprenticeship in navigation is open only to the candidates who are most promising, and it lasts about 20 years. Usually a boy is apprenticed to a male relative. Boys without relatives in the practice pay dearly for the privilege of being instructed. Less than half of those who volunteer to apprentice actually complete the course of training and become navigators. Even fewer are capable of navigating a long solo trip. The apprenticeship is conducted first on land, during lessons in which the learners must memorize large amounts of information, such as the pattern of rising and setting stars for countless routes. Not only is star information taught, but dozens of other topies as well, such as currents, conditions, waves, positions, reefs, weather, and sealife. There is a special hut for these lessons, and mats and stones are used flexibly to represent different relevant environmental elements. Lessons on land are followed by years of practice at sea, in a graduated program of guided practice. The program of apprenticeship for the Puluwat navigators might be seen as most similar to the modern, Western system of medical education.

Although a variety of cultures use intentional instruction as the method of education for the acquisition of valued economic skills, the use of intentional instruction is even more clearly evident in the education of manners, religion, and other socially designed practices. As Fortes (1970) observed, when children learn practical skills, they have their own objective achievement as an evaluation of their progress. However, when the child is learning prayers or humility or magic, the only test for educational progress is the reaction of other people. Other people possess all the information about taboos, charms, terms of address, and all the many and complex aspects that make up the social rules and identity of a people.

Among the Tikopia of Polynesia, parents are considered responsible for the instruction of children in manners, customs, and polite speech (Firth, 1970). In North America Hopi parents strive to create "good hearts" in their children, the feelings that motivate appropriate behavior (Eggan, 1970). In Wogeo, New Guinea, parents believe in singara, "steering" their children's moral development (Hogbin, 1970). Parents of the Chaga tribe in Tanzania begin drilling their three-year-olds 
in the three classes of names that all family members have. By six years of age the children have been taught terms of address and new and elaborate manners (Raum, 1970). In Uganda etiquette is also drummed into the children of the Ganda people. They must master phrases of greeting and farewell, polite gestures, and the rules of gift giving; errors are severely punished (Mair, 1934). The Tallensi people place a high value on their ancestor cult and acknowledge the positive obligation they have in transmitting it to the next generation. One chief informed Fortes, "This is my child, and I am teaching him uprightness. If he is about to do anything that is not seemly I tell him, so that when he grows up he will know upright ways" (Fortes, 1970, p. 23).

Initiation rites are clearly an example of the intentional teaching of adolescents. During adolescent initiation, Chaga boys must endure the adults' relentless repetition of ethical teaching (Raum, 1970). Special isolation, taboos, and vocabulary instruction are required of the apprentice shamans among Eskimo boys (Bernhard, 1988). For the vision quest of the North American Sioux, adults require that boys experience four days of fasting while alone and naked in a small, deep pit. Once a boy has survived the initiation, an elderly teacher informs him that he is now a man and may take a new name (Lame Deer and Erdoes, 1972). The boys of the Sambia people in the New Guinea Highlands are required to undergo a strict initiation that lasts from 7 to 17 years of age. During these years initiates are totally isolated from uninitiated males and from all of the females of the community. Adult males teach the initiates by telling them ritualized stories concerning masculine values and taboos. They also stage horrible events to deliberately frighten the boys so that they will listen even more carefully. Furthermore, the men demand that the boys participate in nightly ritualized homosexual activities throughout this multiyear period in order to develop masculinity (Herdt, 1981). In these and other initiation rites it is clear that adults are intentionally orchestrating experiences to create a deep impression on the children, one that will last a lifetime.

Mead (1930) reports that although Manus parents expect the natural development of physical grace, they intentionally teach two important cultural values: property rights and modesty. For example, since the rules of possession are extremely important to adults, they directly and repeatedly instruct children in them. Children are explicitly taught not to touch articles they do not own. Just one act of damage to another's property results in a major public scene. It begins with drumming to the entire community, alerting everyone that a meeting will soon take place. At that time the crimes of the errant child are announced, and the young offender is denounced and shamed, humiliated before the entire Manus community. This is not learning about cultural values by inference. This is learning by direct, intentional instruction about the rules of society.

Similarly, Lutz (1983) reports that the Ifaluk of Micronesia have a cultural value of cooperation and nonaggression. Parents see themselves as responsible for ensuring that their children are worthy members of society. They use lectures and long discussions on Ifaluk customs and correct behavior as one tool of instruction. Another tool is the elicitation of the emotion they call metagu. Children are encouraged to feel metagu in the presence of strangers, or whenever they should feel 


\section{Ann C. Kruger and Michael Tomasello}

shame. If a child does not demonstrate the appropriate metagu reaction to a situation, her parents issue a call to a ghostly figure (tarita), beseeching her to come forward from her inland hiding place. The child knows that this phantom kidnaps and eats little children, and the child understands that her parents have called the ghost because of her misbehavior. The dreaded ghost (a female household member in horrific disguise) appears outside the house, on cue, and the terrified child clings for parental protection. This emotional state in the child is considered to be a very good moment for instruction in the experience of metagu.

The examples cited above show adults engaging in formal, intentional instruction of children. These are verbal encounters, separate from the daily flow of activity and repeated as necessary until the children's behavior reaches some preestablished criterion. The adults have requirements, and they enforce them. This behavior by adults reflects a belief that children, for some activities and standards, must be trained in the ways of the culture. Obviously, not all ways require teaching, but when the cultural practice is highly valued, complex, or abstract, adults use intentional instruction to ensure that their children will not embarrass them. They want their children to be appropriate, respectable members of society, and so they stay with the children, teaching them the upright ways. In the ethnographies reviewed, covering numerous and far-flung societies, every society used intentional teaching, at least for some very important aspects of cultural life.

\section{The Effect of Intentional Instruction on Cognitive Development}

We have argued and presented evidence that adults in all cultures have beliefs about what children know and how they learn. Adults are motivated to act on those beliefs, whether out of the tender desire for their offspring to be well adjusted, or out of the practical need for their children's help with the economic burdens of life. For love or money, the motivation to affect children's development results in adult involvement in the learning process. Thus the human child, and only the human child, is born into a developmental niche populated by educators. Intentional instruction is a key ingredient in the recipe that creates a normally developing human being.

We see intentional instruction as making its contribution to human development in two main ways. One effect of instruction is to enhance or even enable the child's acquisition of many culturally relevant skills. As we have seen, scaffolding and teaching lead to more effective learning in many domains and with many tasks. To acquire a new skill, children often rely on adults to direct their attention to the right things and to give them feedback about how they are doing. Adults provide the boost children need to learn important cultural tasks efficiently and appropriately.

However, there is a second and more profound effect of intentional instruction. In certain instructional situations, the adult intends for the child to learn in a special way, to adopt a new, more adult-like perspective. Children comprehend the intention of the adult with respect to their own intentions and appropriate the 
adult's understanding. Thus, children experience instructed learning; they have a new understanding that retains the intersubjectivity of the learning situation. As we argued in Tomasello, Kruger, and Ratner (1993), when a child internalizes an adult's intentions, there are dramatic effects on cognitive development.

The origins of this effect on cognitive development can be seen in the earliest days of infancy, when adults treat children as if they have intentions toward other people. Western mothers and their babies engage in a reciprocal smiling and vocalizing game that resembles the turn taking of conversation (Trevarthen, 1979); this rhythmical interaction is richly supported by the mother's structuring, and the baby's behavior is lavishly interpreted by the mother as intentional (Kaye, 1982). Mothers on the Marquesas Islands, by contrast, hold their infants facing out to others in the household, intending the babies to be interactive partners with older children (Martin and Kilpatrick, 1981). Kaluli mothers in Papua New Guinea will occasionally "speak" for their infants in high-pitched voices to entice teenagers to chat with them (Schieffelin, 1990). Around the world the intentional treatment of young children also includes adults' references to entities in the environment. Adults demonstrate the uses of materials, point out features of the environment, and highlight cause-effect relations by gesturing, vocalizing, presenting, and emoting. The adult intends for the child to attend to the object of interest. In these situations adults are behaving as if their babies were mature interactive partners with the intention of conversing. Eventually, as a result of living in this world of intentions and expectations, and being treated accordingly, the child comes to understand the adult, and the self, as intentional: hence, the socalled nine-month-miracle, when for the first time human infants look where adults are looking ( joint attention), feel what adults are feeling (social referencing), and do what adults are doing (imitation). By figuring out the intentions of the other people in their world, and by adopting these intentions as their own, children are cognitively changed. The new understanding of persons as intentional agents enables older infants to acquire more complex abilities, such as the use of symbols (Tomasello, in press), and perhaps to form a self concept (Tomasello, 1993).

The effect of intentional instruction does not stop at the end of infancy. Around the age of four years, the child understands that other people have unique, subjective perspectives, ones that often differ from her own. This development in the child's social cognition supports even more elaborate cultural learning, often in the context of one of the forms of intentional instruction. For example, the child may understand that she and her mother have different minds and different perspectives on a task, and they converse about the task in a dialogue exploring these differences. The two work together, in a manner controlled by the adult, to reach a meeting of the minds. The adult intends to affect the child's understanding, the child is aware of this intention, and the child works to create a new understanding of the task, one based on the adult's intentions. In true instructed learning the child leaves the interaction with an internalized dialogue that represents a coordination of the participants' mental representations during the instructional process (Vygotsky, 1978).

As an aside, we should also mention that intentional instruction of the type we 


\section{Ann C. Kruger and Michael Tomasello}

have been describing can also have profound effects on the cognitive development of other animal species. For example, when apes receive intentional instruction from humans - of a type they do not experience in their natural habitats - some significant changes take place in the nature of their cognitive and social cognitive skills (Tomasello, Savage-Rumbaugh, and Kruger, 1993; see Call and Tomasello, in press, for a review).

\section{Implications for Education}

We have focused here on the beliefs and practices of educators. However, it is important to recognize that in any instructional encounter there are at least two different individuals present - teacher and learner - with different comprehensions of the task, different plans about how to proceed, different understandings of the other person and of what that person understands. In past educational practice, only one of these differences between teacher and learner was emphasized: their mismatched comprehension of the task. For generations it was held that the teacher understands, the learner is ignorant, and the goal of education is to pass understanding from the teacher to the learner. This view of the empty-headed pupil has been abandoned by many lately in favor of a more generous alternative. Gardner (1991), for example, argues that children construct naive theories of how the world works. Their so-called unschooled minds are not empty, just less developed than those of more educated people. This variation on the Piagetian view of the child's mind must now be expanded to include children's naive theories of other persons as an important part of the process, as we emphasized in our original formulation of the theory of cultural learning. What we have attempted to emphasize here is that to understand and enhance educational practice, this fuller model of the child's mind must be considered in tandem with a model of the instructor's theory of children, and their minds and learning skills, and how this affects their choice of pedagogical method.

In Olson and Astington's (1993) view, instruction involves complex social cognitive processes. For teachers to be effective, their thinking must integrate a representation of the goal of the task with a representation of the learner's understanding, and they must continuously monitor the effect of feedback and prompts on the learner's progress. This instructional process also may be different for different kinds of tasks. If the point is to teach the learner how to do something, such as prepare tortillas, then teachers must craft their physical demonstrations, monitoring, and feedback accordingly. If the point is to teach the learner how to think about something, such as how to judge whether the current and wind speed favor a long sailing journey, then teachers must craft interpersonal interactions such as discussions with the learner which will prompt the learner to consider and criticize alternatives. A further distinction may be made between teaching students to think about facts and teaching them to think about perspectives. Phelps and Damon (1989) argue that when faced with the challenge of learning facts, such as the multiplication tables, no shift in a learner's perspective is really needed. The facts 
of multiplication are "out there" in the culture; the learner just needs to get them. This information can thus be learned more or less individually, assuming the culture makes it available. However, when the task requires shifts in perspective-taking, such as understanding the concept of proportion (this is relative to that), children learn the concept much more efficiently and deeply through an intersubjective interaction with another person. Learning concepts that rely on perspective is facilitated by the comparison and negotiation of different points of view in social interaction. Thus the more important it is for the child to adopt a second perspective, to see things in a new way - the cultural way - the more likely it is that the adult will intentionally instruct. Instructors' theories of domains of learning, and how these interact with children's learning skills, are therefore an important part of the picture as well.

In our theory of cultural learning (see Tomasello, Kruger, and Ratner, 1993) we emphasized the aspect of the process that we felt cultural psychology had neglected: the child's cognition, especially social cognition. This led us to underemphasize the structuring role of culture and the important part played by intentional instruction. We have attempted to redress the balance here by explicitly describing some of the ways that cultures shape the development of human children, especially through the intentional instruction of others. As a speciesuniversal and species-specific developmental niche, culture is an integral part of the process whereby human children become human adults.

\section{References}

Bernhard, J. G. (1988). Primates in the classroom: An evolutionary perspective on children's education. Amherst: University of Massachusetts Press.

Boesch, C. (1991). Teaching in wild chimpanzees. Animal Behavior, 41, 530-532.

Boesch. C. (1993). Aspects of transmission of tool use in wild chimpanzees. In K. Gibson and T. Ingold (Eds.), Tools, language, and cognition in human evolution. New York: Cambridge University Press.

Bourdieu, P. (1977). Outline of a theory of practice. Cambridge, England: Cambridge University Press.

Bruner, J. S. (1972). Nature and uses of immaturity. American Psychologist, 27, 687-708. Bruner, J. S. (1993). Do we "acquire" culture or vice versa? Behavioral and Brain Sciences. 16. $515-516$.

Call, J. and Tomasello, M. (in press). The role of humans in the cognitive development of apes. In A. Russom, K. Bard, and S. Parker (Eds.), Reaching into thought: The minds of the great apes. New York: Cambridge University Press.

Caro, T. M. and Hauser, M. D. (1992) Is there evidence of teaching in nonhuman animals? Quarterly Review of Biology, 67, 171-174.

Childs, C. P. and Greenfield, P. M. (1980). Informal modes of learning and teaching: The case of Zinacanteco weaving. In N. Warren (Ed.), Studies in cross-cultural psychology (Vol. 2) (pp. 269-316). London: Academic Press.

Cole, M. (1989). Cultural psychology: A once and future discipline? In J. Berman (Ed.). 
Nebraska symposium on motivation, 1989: Cross-cultural perspectives (pp. 279-335). Lincoln: University of Nebraska Press.

Eggan, D. (1970). Instruction and affect in Hopi cultural continuity. In J. Middleton (Ed.), From child to adult: Studies in the anthropology of education (pp. 109-133). Garden City, NY: Natural History Press.

Firth, R. (1970). Education in Tikopia. In J. Middleton (Ed.), From child to adult: Studies in the anthropology of education (pp. 75-90). Garden City, NY: Natural History Press.

Foreman, E. A. (1993). What is the difference between cognitive and sociocultural psychology? Behavioral and Brain Sciences, 16, 518-519.

Fortes, M. (1970). Social and psychological aspects of education in Taleland. In J. Middleton (Ed.), From child to adult: Studies in the anthropology of education (pp. 14-74). Garden City, NY: Natural History Press.

Gardner, H. (1991). The unschooled mind: How children think and how schools should teach. New York: Basic Books.

Gauvain, M. (in press). Thinking in niches: Sociocultural influences on cognitive development. Human Development.

Gladwin, T. (1970). East is a big bird: Navigation and logic on Puluwat Atoll. Cambridge: Harvard University Press.

Goodall, J. (1986). The chimpanzees of Gombe: Patterns of behavior. Cambridge: Harvard University Press.

Greenfield, P. M. and Lave, J. (1982). Cognitive aspects of informal education. In D. Wagner and H. Stevenson (Eds.), Cultural perspectives on child development (pp. 181-207). San Francisco: Freeman.

Herdt, G. H. (1981). Guardians of the flutes: Idioms of masculinity. New York: Columbia University Press.

Hogbin, H. I. (1970). A New Guinea childhood: From weaning till the eighth year in Wogeo. In J. Middleton (Ed.), From child to adult: Studies in the anthropology of education (pp. 134-162). Garden City, NY: Natural History Press.

Howard, A. (1970). Learning to be Rotuman. New York: Teachers College Press.

Ingold, T. (1993). A social anthropological view. Behavioral and Brain Sciences, 16, 526527.

Kaye, K. (1982). The mental and social life of babies: How parents create persons. Chicago: University of Chicago Press.

Konner, M. (1981). Evolution of human behavior development. In R. H. Munroe, R. L. Munroe, and B. B. Whiting (Eds.), Handbook of cross-cultural human development (pp. 351). New York: Garland STPM Press.

Konner, M. (1982). The tangled wing: Biological constraints on the human spirit. New York: Holt, Rinehart and Winston.

Lame Deer, J. and Erdoes, R. (1972). Lame Deer, seeker of visions. New York: Simon and Schuster.

Lave, J. and Wenger, E. (1991). Situated learning: Legitimate peripheral participation. New York: Cambridge University Press.

Lutz, C. (1983). Parental goals, ethnopsychology, and the development of emotional meaning. Ethos, 11, 246-262.

Mair, L. P. (1934). An African people in the twentieth century. London: Routledge.

Martini, M. and Kirkpatrick, J. (1981). Early interactions in the Marquesas Islands. In T. M. Field, A. M. Sostek, P. Vietze, and P. H. Leiderman (Eds.), Culture and early interactions ( pp. 189-213). Hillsdale, NJ: Lawrence Erlbaum.

Mead, M. (1930). Growing up in New Guinea. New York: Mentor. 
Ochs, E. (1988). Culture and language development: Language acquisition and language socialization in a Samoan village. New York: Cambridge University Press.

Olson. D. R. and Astington, J. W. (1993). Cultural learning and the educational process. Behavioral and Brain Sciences, 16, 531-532.

Phelps, E. and Damon, W. (1989). Problem solving with equals: Peer collaboration as a context for learning mathematics and spatial concepts. Journal of Educational Psychology. 81, 639-646.

Quinn. N. and Strauss, C. (1994). A cognitive framework for a unified theory of culture. Unpublished manuscript.

Raum, O. (1970). Some aspects of the indigenous education among the Chaga. In J. Middleton (Ed.). From child to adult: Studies in the anthropology of education (pp. 91-108). Garden City, NY: Natural History Press.

Rogoff. B. (1990). Apprenticeship in thinking: Cognitive development in social context. New York: Oxford University Press.

Rogoff, B., Chavajay, P., and Matusov, E. (1993). Questioning assumptions about culture and individuals. Behavioral and Brain Sciences, 16, 533-534.

Schieffelin, B. B. (1990). The give and take of everyday life: Language socialization of Kaluli children. Cambridge, England: Cambridge University Press.

Shweder, R. A. (1990). Cultural psychology - what is it? In J. W. Stigler, R. A. Shweder, and G. Herdt (Eds.). Cultural psychology: Essays on comparative human development (pp. 143). New York: Cambridge University Press.

Super, C. M. (1981). Behavioral development in infancy. In R. H. Munroe, R. L. Munroe, and B. B. Whiting (Eds.), Handbook of cross-cultural human development (pp. 181-270).

New York: Garland STPM Press.

Super, C. M. and Harkness, S. (1986). The developmental niche: A conceptualization at the interface of child and culture. International Journal of Behavioral Development, 9 , 545-569.

Tomasello, M. (1990). Cultural transmission in the tool use and communicatory signaling of chimpanzees? In S. Parker and K. Gibson (Eds.), Language and intelligence in monkeys and apes: Comparative developmental perspectives (pp. 274-311). New York: Cambridge University Press.

Tomasello, M. (1993). On the interpersonal origins of self-concept. In U. Neisser (Ed.). The perceived self (pp. 174-182). New York: Cambridge University Press.

Tomasello, M. (1994). The question of chimpanzee culture. In R. Wrangham, W. McGrew, F. deWaal, and P. Heltne (Eds.), Chimpanzee cultures (pp. 301-317). Cambridge: Harvard University Press.

Tomasello, M. (in press). Joint attention as social cognition. In C. Moore and P. Dunham (Eds.), Joint attention: Its origins and role in development. Hillsdale: Lawrence Erlbaum.

Tomasello, M., Kruger, A. C., and Ratner, H. H. (1993). Cultural learning. Behavioral and Brain Sciences, 16, 495-552.

Tomasello, M., Savage-Rumbaugh, S., and Kruger, A. C. (1993). Imitative learning of actions on objects by children, chimpanzees, and enculturated chimpanzees. Child Development, 64, 1688-1705.

Trevarthen, C. (1979). Communication and cooperation in early infancy: A description of primary intersubjectivity. In M. Bullowa (Ed.), Before speech: The beginning of interpersonal communication (pp. 321-347). Cambridge, England: Cambridge University Press.

Vygotsky, L. S. (1978). Mind in society. Cambridge: Harvard University Press.

Wrangham, R., McGrew. W., deWaal, F., and Heltne, P. (1994). Chimpanzee cultures. Cambridge: Harvard University Press. 